\title{
Analysis of Analytic Hierarchy Process to Build a Cities Evaluation System Based on Smart Growth
}

\author{
Mengyue Yang, Yuwei Zhang \\ School of Information, Beijing Wuzi University, Beijing, China \\ Email:2545801883@qq.com
}

How to cite this paper: Yang, M. Y., \& Zhang, Y. W. (2017). Analysis of Analytic Hierarchy Process to Build a Cities Evaluation System Based on Smart Growth. Current Urban Studies, 5, 483-489.

https://doi.org/10.4236/cus.2017.54027

Received: November 14, 2017

Accepted: December 9, 2017

Published: December 12, 2017

Copyright $(0) 2017$ by authors and Scientific Research Publishing Inc. This work is licensed under the Creative Commons Attribution International License (CC BY 4.0).

http://creativecommons.org/licenses/by/4.0/

\begin{abstract}
Smart growth is an urban planning theory that originated in 1990's, which has been gradually focused on by researchers. The theory is in coincidence with China's strategies that promote urbanization and the transformation of urban development. The goal of this paper is to apply analytic hierarchy process to build an evaluation system of cities based on smart growth. After analyzing the factors that need to be taken into account, we build a hierarchical model and put different weight on different factors that compose the evaluation system of cities. Finally, we use smart growth mode for Jinchang city and point out that the scientific urban planning should be improved in the way of smart growth. The results of this paper can provide some decision-making references for relevant departments.
\end{abstract}

\section{Keywords}

Smart Growth, AHP, Evaluation System, Jinchang City

\section{Introduction}

Smart growth looks at urban construction, and it includes three sustainability indicators-economically prosperous, socially equitable, and environmentally sustainable. The ten principles for smart growth are as follows (Duany \& Andres, 2010): mix land uses; take advantage of compact building design; and create a range of housing opportunities and choices and so on. The theory of smart growth is an urban planning theory, which was put forward by the American planning community to curb the persistence of urban expansion and reduce farmland losses around urban centers in the 1990s. After practicing a long period, smart growth theory is more complete now, including improving social fairness, creating a more suitable residential environment, coordinating the land 
use and functional combination of cities and towns, and it includes a new research perspective for the overall urban-rural development.

China's National Bureau of Statistics released data in early 2017 that the resident population in urban areas was 792.88 million, an increase of 21.82 million from the previous year, and the proportion of urban population to the total population (urbanization rate) was $57.35 \%$. According to the forecast, China's urbanization will be steadily pushed forward during the "13th Five-Year Plan" period, and its urbanization rate in China will reach 63\% by 2020 (Li, 2017). With the gradual progress of urbanization, urban population can lead to a sharp rise in urban construction land, over exploitation of cultivated land and unsustainable development of urban waste of resources. Therefore, smart growth is very necessary to realize the overall development of urban and rural areas.

General Secretary Xi Dada mentioned the overall goal in his important speeches of improving people's livelihood and innovating social governance in 2016. Concrete content is letting the people love life, having a better education and looking forward to children growing better, working better, living better and so on (China Daily, 2016). This is the same as the goal of smart growth. At the same time, with the popularization of the development concept of promoting new urbanization and urban transformation in our country, we can see that urban construction based on smart growth is an inevitable choice in the process of urbanization in our country, which provides a new direction for urban construction (Tang, 2009).

The theory has been used widely overseas now. However, there are few researches in our country. Domestic scholars pay more attention to the introduction of the concept of Smart growth theory. Then, there are few studies on the evaluation system and specific indicators of Smart growth in cities. Long Jing (Long, 2013) built the evaluation index system of land utilization based on Smart growth; Han Gang (Han, \& Yuan, \& Wang, 2017) has put forward that Chinese cities should promote the planning and construction of cities with smarter ways in land growth, implement effective public transport planning and policies, and implement the development plans of neighborhoods and communities fully; Shen Jinzhen (Shen, 2017) mentioned that the idea of promoting smart growth will become an inevitable requirement and an important starting point to facilitate the transformation of urban development in the smart city.

On the whole, there is no unified method for the comprehensive evaluation of smart growth. Based on the characteristics of smart growth theory, this paper constructs the index evaluation system by AHP, then analyzes the current situation of smart city development in Jinchang City, Gansu Province, and gives some suggestions finally.

\section{Construct Index System Based on Smart Growth Theory}

The theory of Smart growth involves many aspects of people's lives, including land, housing, transportation, people's happiness, environmental sustainability, 
healthy development. Therefore, many factors need to be considered synthetically when evaluate the present state of smart development of a city directly. Next, relationship is complicated between the various factors, so it is also difficult to give the distinction directly and unable to use in practice. In conclusion, integrate and cluster of the areas involved in the theory of smart city growth, and then weight the priorities of the rankings, that is vital of measuring the degree of the development of shrewd measure, and providing future planning reference.

Analytic hierarchy process (AHP) is a multi-criteria decision-making method combining qualitative and quantitative analysis. The idea is to decompose complex problems into various elements, and form different levels according to their mutual relations and their affiliation. Elements at the same level play a dominant role in the next level, and are dominated by a higher level of elements meanwhile. At the highest level, there is only one element, which represents the goal to be achieved by policymakers. The middle level is generally a criterion, or sub-criterion, which is judge whether reached or not, and a lowest level indicates various indicators or measures to be taken to solve the problem.

\subsection{Establish Hierarchy Model}

Establishing hierarchy model of the problem is the most important step in the AHP method. We take the promotion of smart city growth as the target level; the guideline level is the principles of smart growth; and the indicator level is the 15 factor indicators which is done by the data is dimensionally reduced and finally obtained through the SPSS software factor analysis function with the data type of the statistical yearbook. Build the following hierarchy model finally, as is shown in Figure 1.

\subsection{Index Weight Judgment and Test}

With the principle of comparison of two indicators, ten experts understanding the Chinese national conditions and astute urban growth theory expert group define the weights of indicators at all levels on the basis of the 1 to 9 scale contrast valuation assignment. The last we average weight given by the experts and get the relationship between the various indicators shown in Table 1.

We can be construct corresponding judgment matrix according to the relationship between the indicators table, and then judge the consistency of the matrix test. If the CI value is greater than 0.1, we need to reset the contrast between the two indicators. $A_{i}$ represents the weight value of each indicator, and draws the test results of weight index of each level. After testing, the values of CR are less than 0.1 , indicating that the matrix composed of the indicators set by expert group is relatively consistent, and the calculated values of $A_{i}$ is valid, indicating modification of the relative weight value can stop.

\subsection{Calculate the Weight of Indicators at All Layers}

Calculate the weight of each layer indicator for A. The weights of layer B and C 


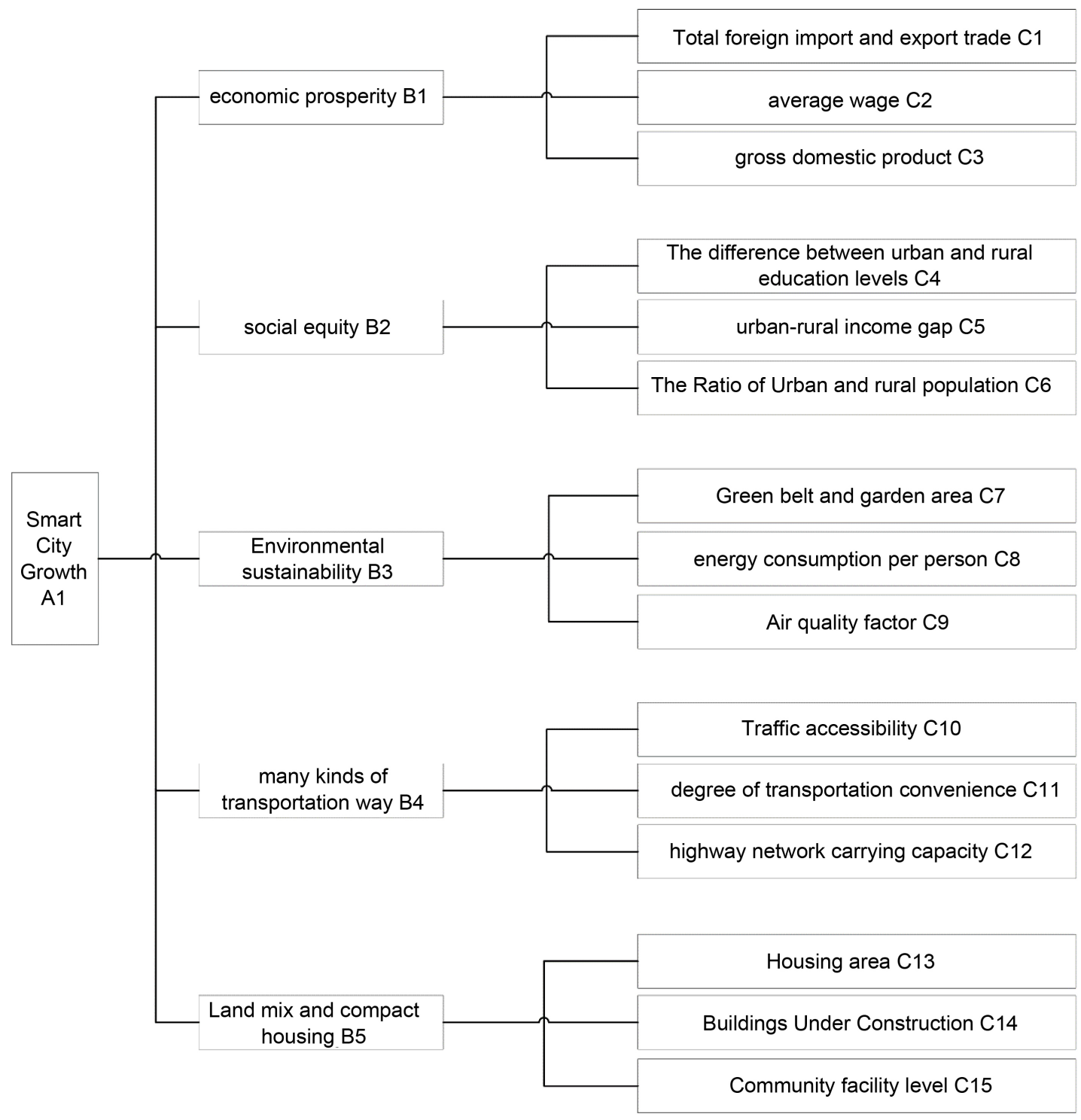

Figure 1. Hierarchy model.

Table 1. Comparison table between two indexes in each layer.

\begin{tabular}{ccccccccc}
\hline$B_{1} / B_{2}$ & $B_{1} / B_{3}$ & $B_{1} / B_{4}$ & $B_{1} / B_{5}$ & $B_{2} / B_{3}$ & $B_{2} / B_{4}$ & $B_{2} / B_{5}$ & $B_{3} / B_{4}$ & $B_{3} / B_{5}$ \\
\hline $1 / 3$ & $1 / 5$ & 1 & $1 / 3$ & $1 / 3$ & $1 / 3$ & 3 & 5 & 1 \\
\hline$B_{4} / B_{5}$ & $C_{1} / C_{2}$ & $C_{1} / C_{3}$ & $C_{2} / C_{3}$ & $C_{4} / C_{5}$ & $C_{4} / C_{6}$ & $C_{5} / C_{6}$ & $C_{7} / C_{8}$ & $C_{7} / C_{9}$ \\
\hline 3 & 3 & 5 & 3 & $1 / 3$ & 3 & 5 & $1 / 3$ & $1 / 5$ \\
\hline$C_{8} / C_{9}$ & $C_{10} / C_{11}$ & $C_{10} / C_{12}$ & $C_{11} / C_{12}$ & $C_{13} / C_{14}$ & $C_{13} / C_{15}$ & $C_{14} / C_{15}$ & & \\
\hline $1 / 3$ & $1 / 3$ & 1 & 3 & $1 / 3$ & $1 / 7$ & $1 / 3$ & &
\end{tabular}

are shown in Table 2 and Table 3.

Finally 15 indicators covering the development of smart growth in C-layer is chosen. The weight of each indicator shows how much it contributes to smart development. They can be used as a guide to lead smart. 
Table 2. Weights of layers B.

\begin{tabular}{ccccccc}
\hline B layer & B & $B_{1}$ & $B_{2}$ & $B_{3}$ & $B_{4}$ & $B_{5}$ \\
\hline weight & 1 & 0.0761 & 0.1672 & 0.4007 & 0.2106 & 0.1454 \\
\hline
\end{tabular}

Table 3. Weights of layer C.

\begin{tabular}{ccccccccc}
\hline C layer & $C$ & $C_{1}$ & $C_{2}$ & $C_{3}$ & $C_{4}$ & $C_{5}$ & $C_{6}$ & $C_{7}$ \\
\hline weight & 1 & 0.0485 & 0.0197 & 0.0080 & 0.0432 & 0.1065 & 0.0175 & 0.0420 \\
\hline C layer & $C_{8}$ & $C_{9}$ & $C_{10}$ & $C_{11}$ & $C_{12}$ & $C_{13}$ & $C_{14}$ & $C_{15}$ \\
\hline weight & 0.1035 & 0.2552 & 0.0421 & 0.1263 & 0.0421 & 0.0128 & 0.0353 & 0.0973 \\
\hline
\end{tabular}

\section{Instances Analysis}

\subsection{Jinchang Introduction}

Jinchang is an industrial city in Gansu province the northwest of China with a population of 460,000 which is a mid-sized city. Jinchang is an oasis in the desert without exaggeration. It has 2575 square kilometers of the oasis and 2535 square kilometers of the desert around it. Jinchang is one of the National civilized cities in China (Wikipedia, 2017) (National civilized city is the highest and the most comprehensive honor given by the relevant authority of China, reflecting the overall level of civilization of the city) and some indexes of three E's of sustainability or the ten principles of smart growth theory can be easily chosen from the assessment standard to measure the success of smart growth of the city. So, we introduce Jinchang as an example for analysis.

Growth Persistently high natural population growth is the most significant cause of urban population growth, though the degree of its importance varies among countries. Jinchang, one of the largest cities in Gansu province, grew at an average of 5.6\% rate per annum between 1982 and 2010, even though it was built in 1981. Over the next 20 to 30 years, the population in general and the urban population in particular are expected to increase at an even higher rate.

Jinchang also attracted substantial new investments over the past two to three decades. This city has received some projects in real estate, telecommunication, and industries at home and abroad. Although median incomes in Jinchang exceed the Gansu province average, its rent levels and housing costs remain well below the provincial mean. Under these circumstances, its urban neighborhoods are sufficient to cater for a doubling of the city's population, and little evidence of a shortage of affordable accommodation. Containment policies are unlikely to enact to boost property values sufficiently in the foreseeable future. The current urban development pattern in Jinchang, which is dominated by unlimited outward extension, low-density residential developments, and haphazard patterns, is unacceptable. This pattern is destroying prime agricultural and environmentally sensitive lands, while increasing air pollution and traffic congestion. These problems can be tackled by the adoption of smart growth principles and rapidly growing Jinchang needs to adopt smart growth initiatives. Smart growth prin- 
ciples promote compact urban development by concentrating growth in existing urban areas. The central idea of smart growth is that structured and strategic planning supports economic growth, addresses community needs, and protects the environment.

\subsection{Comparison}

According to Jinchang Bureau of Statistics of the People's Republic of China and personnel views, each indicator of smart growth was scored and use $s_{i}$ to represent. The actual score table is shown in Table 4.

The measure of the degree of smart growth in the city is

$$
F=\sum_{i=1}^{15} C_{i} s_{i}
$$

According to Table 3 and Table 4, Jinchang get 79 points. It is not enough smart. While vigorously developing economy and supporting the development of local small and medium-sized enterprises by government, improvements can also be made in the following aspects:

1) Improve air quality, which is related to the city's geographical environment and the urban economic structure. Plant trees and build more irrigation canals.

2) Improve traffic convenience. Smart growth encourages make more use of public transport system to travel, including public transport, car partnerships, cycling and walking. The urban transport system of Jinchang is not perfect and the residents structure is not much reasonable: the city center is inaccessible to other places.

3) Increase the green belt and parkland. Jinchang is located in the Gobi. Its natural ecological environment is relatively fragile and its green vegetation is relatively small. The protection of urban green area and open space should also be focused.

4) Build a compact home. The process of urbanization is accelerating. However, the land resources in Jinchang are limited. The planning and allocation of land are not reasonable enough, and the intensive use of land is also at a low level. The urban population still spread and the intensity of land use urgently needs to be strengthened.

\section{Conclusion}

The goal of this paper is to apply analytic hierarchy process to build an evaluation system of cities based on smart growth. Through the SPSS factor analysis

Table 4. Score table of indicators.

\begin{tabular}{ccccccccc}
\hline Indicators & $s_{1}$ & $s_{2}$ & $s_{3}$ & $s_{4}$ & $s_{5}$ & $s_{6}$ & $s_{7}$ & $s_{8}$ \\
\hline Score & 71 & 60 & 67 & 77 & 77 & 72 & 60 & 87 \\
\hline Index & $s_{9}$ & $s_{10}$ & $s_{11}$ & $s_{12}$ & $s_{13}$ & $s_{14}$ & $s_{15}$ & \\
\hline Score & 80 & 87 & 84 & 73 & 70 & 86 & 88 & \\
\hline
\end{tabular}


and AHP, the weights of each indicator are obtained. Taking Jinchang City as an example, the calculation of the degree of smart growth is carried out. Based on the calculation results, some suggestions are provided for the future development of Jinchang. As the process of urbanization accelerates, more and more rural population will come to cities, which will have a powerful impact on various resources in cities. Therefore, it is of great significance for the city to carry out the construction of smart city in advance. The results of this paper can provide reference for the relevant departments to make decisions.

\section{References}

China Daily (2016). Xi Dada General Secretary Series Important Speeches Reader (2016 Edition). http://theory.people.com.cn/n1/2016/0506/c40531-28329410.html

Duany, \& Andres. (2010). Jeff Speck and Mike Lydon. The Smart Growth Manual. New York: McGraw-Hill.

Han, G., \& Yuan, J. D., \& Wang, Z. B. (2017). Foreign Study on the Compact Cities and Its Enlightenments to China. World Regional Study, 56-64.

Li, R. F. (2017). 2016-2020 Study on the Growth of Urbanization in China. http://www.rmzxb.com.cn/c/2017-01-05/1265270.shtml

Long, J. (2013). The Study of Urban-Rural Land Use Smart Growth Based on BP Neural Neyworks. Ph.D., Nanning: Guangxi Teachers Education University.

Shen, J. Z. (2017). Smart Cities to Promote Smart Growth. Front, 56-59.

Tang, X. L. (2009). Research Summary of “Smart Growth”. Urban Issues, 98-102.

Wikipedia (2017). Jinchang. https://en.wikipedia.org/wiki/Jinchang 